ORIGINAL ARTICLE

\title{
Optimal Conditions for Obtaining Valid Step Count Measurements in Hospitalized Patients with Abnormal Gait
}

\author{
Tomohiro Oba, MS, RPT a Hiroaki Iwase, MS, RPT ${ }^{b}$ Yoshitake Oshima, PhD ${ }^{\mathrm{c}}$ \\ Junya Miyazaki, PhD, RPT ${ }^{b}$ and Kojiro Ishii, PhD ${ }^{d}$
}

\begin{abstract}
Objective: This study investigated the optimum conditions for obtaining valid step-count measurements for patients with abnormal gait. Methods: Subjects comprised 61 hospitalized patients with abnormal gait. Four different devices were tested: Active Style Pro (AS), Walking Style (WS), Lifecorder PLUS, and Steps. The same device type was attached to the waist on both the affected and the unaffected side. Patients then walked $25 \mathrm{~m}$ at a comfortable speed. This test was repeated four times, once for each device. The measurement error (ME) and walking parameters (gait velocity, step length, and cadence) were calculated from the test data. ME scores smaller than $3 \%$ and $10 \%$ were classified as valid: scores above these standards were classified as invalid. Walking parameter values that identified the invalid group with a specificity of 0.95 were set as the cut-off velocity (COV), the cut-off step length (COS), and the cut-off cadence. Sensitivity values $>0.40$ and positive predictive values $>80 \%$ were then set as necessary conditions. Results: $\mathrm{COV}$ values were $0.90 \mathrm{~m} / \mathrm{s}$ (AS on the unaffected side at $3 \% \mathrm{ME}$ and $\mathrm{AS}$ on the affected side or the unaffected side at $10 \% \mathrm{ME}$ ), $0.92 \mathrm{~m} / \mathrm{s}$ (WS on the unaffected side at $10 \% \mathrm{ME}$ ), and $0.98 \mathrm{~m} / \mathrm{s}$ (WS on the affected side at $3 \% \mathrm{ME}$ ). COS values were $0.50 \mathrm{~m}$ (AS on the affected side at $10 \% \mathrm{ME}$ ) and $0.52 \mathrm{~m}$ (AS on the unaffected side at 3\% ME). Conclusion: The most accurate measurements were obtained using AS attached to the unaffected side with a gait velocity of $>0.90 \mathrm{~m} / \mathrm{s}$.
\end{abstract}

Key words: activity monitor; gait disorder; pedometer; step count validity; walking parameter

\section{INTRODUCTION}

Hospitalized patients undergoing rehabilitation may reduce their levels of physical activity for various reasons. ${ }^{1)}$ This is especially true for patients with cerebrovascular and/ or musculoskeletal diseases because they often have walking disabilities. ${ }^{1,2)}$ Lower levels of physical activity may result in secondary chronic diseases and disuse syndrome, deterioration in the activities of daily living, and increased risks of institutionalization and death. ${ }^{3)}$ Increasing the level physical activity may prevent disuse syndrome, may contribute to the improvement of physical function, and may enhance the therapeutic value of rehabilitation. ${ }^{4)}$ Moreover, physical ac- tivity may help prevent the onset and aggravation of chronic diseases ${ }^{5)}$ The amount of physical activity performed is an important factor in the treatment of hospitalized patients undergoing rehabilitation.

Among physical activities, walking is the most widely performed. The number of steps taken is widely recognized as a simple and objective indicator of the amount of walking that has been performed; therefore, it is an indicator of the walking ability of an individual. Furthermore, it is useful to evaluate the number of steps taken by hospitalized patients. This is necessary because stable walking is essential for independent daily living. The ability to walk is essential to execute the full range of activities of daily living. $\left.{ }^{6}\right)$ In ad-

Received: July 31, 2017, Accepted: November 29, 2017, Published online: December 27,2017

${ }^{a}$ Graduate School of Health and Sports Science, Doshisha University, Kyotanabe, Kyoto, Japan

${ }^{b}$ Faculty of Health Sciences, Kyoto Tachibana University, Yamashina-ku, Kyoto, Japan

${ }^{\mathrm{c}}$ Faculty of Human and Social Sciences, University of Marketing and Distribution Sciences, Kobe, Hyogo, Japan

d Faculty of Health and Sports Science, Doshisha University, Kyotanabe, Kyoto, Japan

Correspondence: Tomohiro Oba, Furugori 21-206 \#704, Oizumi, Oura, Gunma 370-0536, Japan, E-mail: hrndn660@yahoo.co.jp

Copyright (C) 2017 The Japanese Association of Rehabilitation Medicine 
Table 1. Participant characteristics and walking parameters

\begin{tabular}{|c|c|c|c|c|c|c|c|c|c|c|c|}
\hline & \multirow[t]{2}{*}{$\mathrm{n}$} & \multirow{2}{*}{$\begin{array}{l}\text { Age } \\
\text { (year) }\end{array}$} & \multirow{2}{*}{$\begin{array}{l}\text { Height } \\
(\mathrm{cm})\end{array}$} & \multirow{2}{*}{$\begin{array}{l}\text { Body mass } \\
(\mathrm{kg})\end{array}$} & \multirow{2}{*}{$\begin{array}{c}\text { BMI } \\
\left(\mathrm{kg} / \mathrm{m}^{2}\right)\end{array}$} & \multirow{2}{*}{$\begin{array}{c}\text { Gait velocity } \\
(\mathrm{m} / \mathrm{s})\end{array}$} & \multirow{2}{*}{$\begin{array}{l}\text { Step length } \\
\text { (m) }\end{array}$} & \multirow{2}{*}{$\begin{array}{l}\text { Cadence } \\
\text { (steps/s) }\end{array}$} & \multicolumn{3}{|c|}{ Walking aids } \\
\hline & & & & & & & & & None & Cane & Rollators $^{\mathrm{a}}$ \\
\hline Men & 16 & $\begin{array}{l}76.5 \\
(8.5) \\
\end{array}$ & $\begin{array}{l}162.7 \\
(6.5)\end{array}$ & $\begin{array}{l}59.9 \\
(9.9) \\
\end{array}$ & $\begin{array}{l}22.6 \\
(3.0) \\
\end{array}$ & $\begin{array}{c}0.73 \\
(0.31) \\
\end{array}$ & $\begin{array}{c}0.43 \\
(0.14) \\
\end{array}$ & $\begin{array}{l}1.69 \\
(0.31) \\
\end{array}$ & 7 & 6 & 3 \\
\hline Women & 45 & $\begin{array}{l}80.5 \\
(8.7) \\
\end{array}$ & $\begin{array}{l}150.0 \\
(6.4)\end{array}$ & $\begin{array}{l}48.5 \\
(9.1) \\
\end{array}$ & $\begin{array}{l}21.6 \\
(3.9) \\
\end{array}$ & $\begin{array}{c}0.76 \\
(0.23) \\
\end{array}$ & $\begin{array}{c}0.44 \\
(0.09) \\
\end{array}$ & $\begin{array}{c}1.71 \\
(0.29) \\
\end{array}$ & 21 & 7 & 17 \\
\hline Total & 61 & $\begin{array}{l}79.4 \\
(8.8)\end{array}$ & $\begin{array}{l}153.3 \\
(8.5)\end{array}$ & $\begin{array}{c}51.5 \\
(10.6)\end{array}$ & $\begin{array}{l}21.8 \\
(3.7)\end{array}$ & $\begin{array}{c}0.75 \\
(0.26)\end{array}$ & $\begin{array}{c}0.43 \\
(0.10)\end{array}$ & $\begin{array}{c}1.71 \\
(0.29)\end{array}$ & 28 & 13 & 20 \\
\hline
\end{tabular}

Values are means (standard deviation) or the number of people.

BMI: body mass index.

ancluding wheeled frames.

dition to rehabilitation treatment, therapists often instruct patients to walk for the purpose of self-training to improve their ability to perform the activities of daily living.

To increase the daily number of steps taken, goal-setting methods and self-management methods, including the use of activity monitors such as pedometers, have demonstrated their usefulness. ${ }^{7-9)}$ However, when the authors encouraged hospitalized patients to increase their physical activity and to use activity monitors, it was often found that the steps could not be detected or the number of steps was clearly underestimated. The validity of step-count measurements using activity monitors has been reported for adults, including older adults, without disabilities. ${ }^{10)}$ However, the validity for subjects with walking disabilities remains problematic. ${ }^{9,11)}$ Although previous studies have reported that the validity of the measured number of steps is influenced by the type of device used, the gait velocity, the cadence, and the position of the device (i.e., on the affected or unaffected side), ${ }^{12-14)}$ a consensus regarding optimal device usage has not been reached.

The aim of the current study was to investigate the device type, device position, and walking parameters under which valid step-count measurements can be obtained for patients with abnormal gait.

\section{METHODS}

\section{Participants}

A total of 61 hospitalized patients (16 men and 45 women) with abnormal gait (i.e., an unusual walking pattern different from the normal walking pattern ${ }^{15)}$ resulting from functional and/or morphological abnormalities) and laterality differences in their gait patterns receiving physiotherapy at Kyoto Hakuaikai Social Welfare Corporation, Kyoto Hakuaikai Hospital, were involved in this study. Some participants used walking aids (cane, 13 patients; walker, 20 patients) (Table 1). Patients using certain types of walkers were not chosen for this study because using the walkers had a strong influence on walking patterns. A flow chart of the participant selection process is shown in Fig. 1. The main diagnoses and complications of the participants are shown in Table 2. Thirty-four participants did not have complications, and the others had one or more complications.

\section{Devices}

\section{Active Style Pro HJA-350IT}

The Active Style Pro HJA-350IT (AS) (Omron Healthcare Co., Kyoto, Japan) is a triaxial (anteroposterior, mediolateral, and vertical) accelerometer that is worn on the waist. Based on the raw data, the number of steps taken and amount of physical activity are calculated using a proprietary algorithm specific to the device. When the amplitude of the acceleration becomes equal to or larger than the threshold value and the movement continues for $2 \mathrm{~s}$, the movement is recognized by the device as walking and is counted as steps. ${ }^{16)}$ AS is widely used in Japanese research, ${ }^{10}$ ) and its validity for healthy adults has been established. ${ }^{13)}$

\section{Walking Style HJ-720IT}

Walking Style HJ-720IT (WS) (Omron Healthcare Co., Kyoto, Japan) is a piezoelectric pedometer equipped with accelerometers on two axes (vertical and horizontal) that is worn on the waist or kept in a pocket. It is able to detect steps when it is located in places where it is difficult to maintain the device in the vertical position, such as in a pocket. However, this does not mean that the two axes operate simultaneously. Only one of the two axes senses vertical acceleration at any given time. ${ }^{17)}$ The validity of step-count measurements using WS has been established for healthy adults. ${ }^{18)}$ 
Patients who were hospitalized and received physiotherapy at Kyoto Hakuaikai Hospital

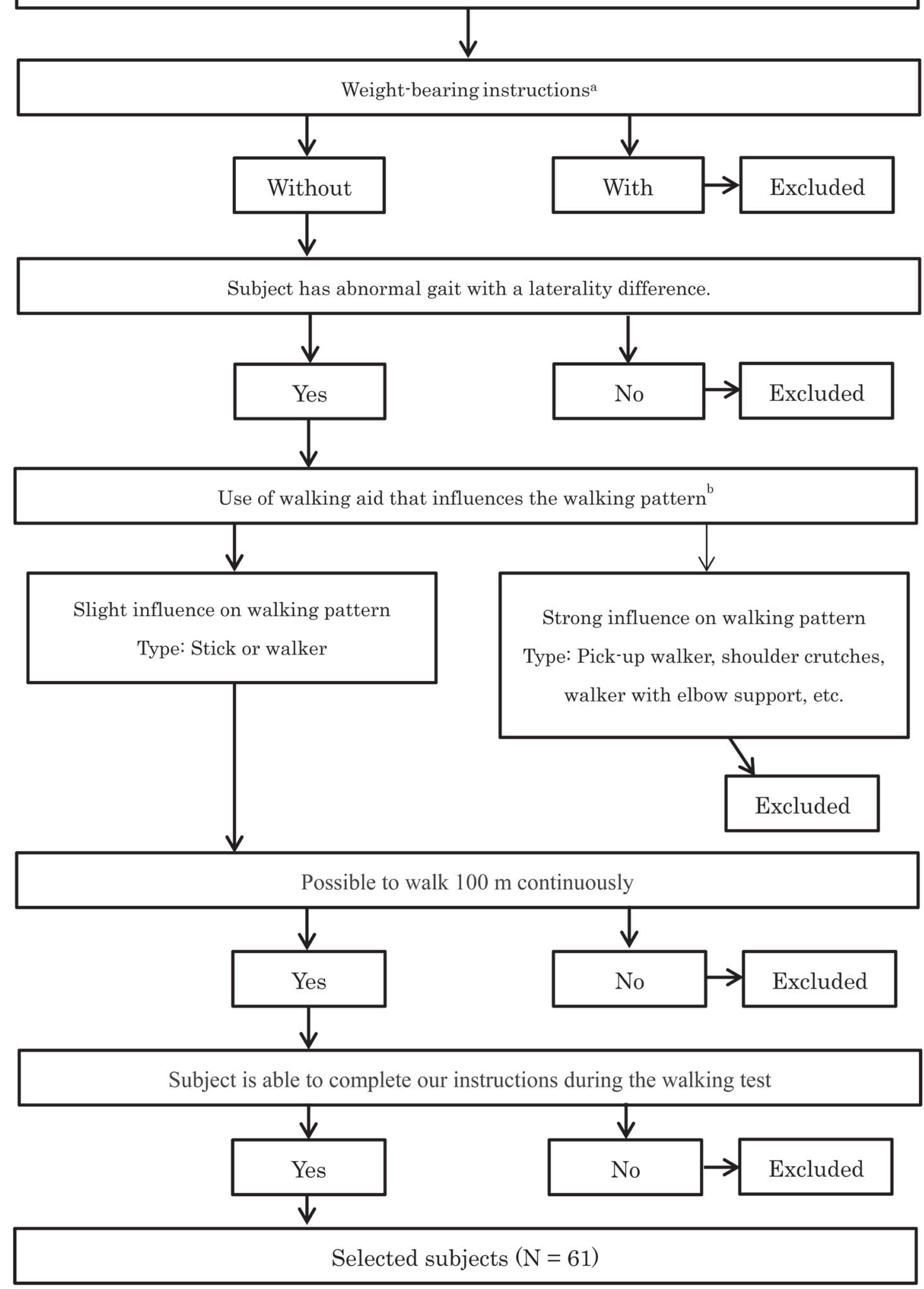

Fig. 1. Flow chart showing selection of the subjects of the current study.

a: Example is one-half weight bearing after femoral fracture.

b: For example, using the pick-up walker involves repeatedly lifting and placing the walker in the foreground. Therefore, its influence on the walking pattern is strong. 
Table 2. Main diagnoses and complications

\begin{tabular}{|c|c|c|c|c|c|c|c|c|c|}
\hline \multirow[t]{2}{*}{ Main diagnosis } & \multicolumn{9}{|c|}{ Complications $^{\mathrm{a}}$} \\
\hline & No. & $\mathrm{FF}$ & CVD & Spondylopathy & $\mathrm{KOA}$ & Post-AHJR & RA & Mental disorder & Others \\
\hline FF & 17 & $1^{\mathrm{b}}$ & 3 & 2 & 2 & 1 & 1 & 3 & \\
\hline Spondylopathy & 6 & 1 & 1 & & 2 & & 1 & & \\
\hline CVD & 5 & & 1 & & 1 & & & & 2 \\
\hline Post-AKJR & 3 & & 1 & 1 & 1 & & 1 & & \\
\hline Post-AHJR & & 1 & & 1 & & & 1 & & 1 \\
\hline Others & 3 & 1 & 1 & 1 & & & & 1 & \\
\hline Total & 34 & 4 & 7 & 5 & 6 & 1 & 4 & 4 & 3 \\
\hline
\end{tabular}

Numbers indicate the number of people.

FF: femoral fracture; CVD: cerebrovascular disease; AKJR: artificial knee joint replacement; AHJR: artificial hip joint replacement; KOA: knee osteoarthritis; RA: rheumatoid arthritis.

${ }^{\mathrm{a} C}$ Cumulative total.

bThis participant had a history of FF on both sides.
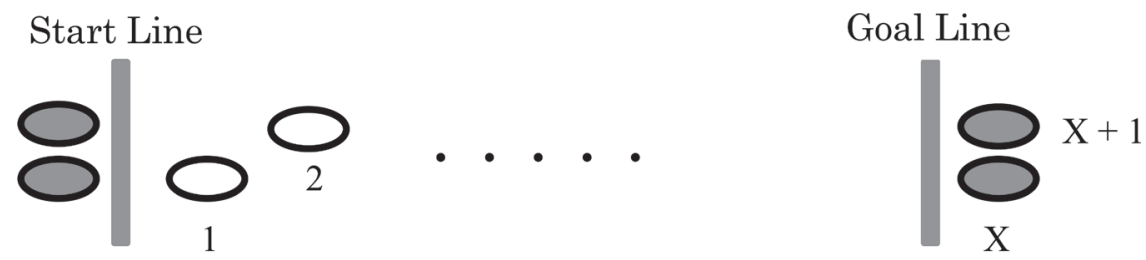

Fig. 2. The 25-meter walking test.

The start and end conditions of the $25-\mathrm{m}$ walk test. $\mathrm{X}$ : the first step after over the goal line.

$\mathrm{X}+1$ : the end step.

\section{Lifecorder PLUS}

Lifecorder PLUS (LC) (Suzuken Co., Nagoya, Japan) is a uniaxial accelerometer that uses vertical acceleration and is worn on the waist. It is popular in many countries because of its reasonable cost and reliability. ${ }^{13)}$

\section{Steps HJ-005}

Steps HJ-005 (ST) (Omron Healthcare Co., Kyoto, Japan) is a spring-levered pedometer that is worn on the waist. Spring-levered pedometers are based on a horizontal, springsuspended lever arm that moves up and down with vertical acceleration of the waist. ${ }^{17)}$ When the movement exceeds a certain magnitude, step counts are detected. Although the sensitivity of the ST can be adjusted by moving a knob from side to side, the knob was maintained in the central position at all times in our study.

\section{The 25-m Walking Test}

Subjects were instructed to walk $25 \mathrm{~m}$ at a comfortable walking speed and then stop and stand still after passing a goal line. In addition, subjects were asked not to place their foot on the goal line: instead, they were instructed to pass the goal line as naturally as possible before stopping. Before the walking test, the subject stood still at the starting line and attached one device to the affected side and another device to the unaffected side on the front of the waist (on the midpoint of the line connecting the anterior superior iliac spine and pubic symphysis). Then, the number of steps on the displays of the devices before beginning the walking test was recorded. During the walking test, the actual number of steps taken was measured using a hand-tally counter, and the walking time was recorded. After the walking test, the number of steps tabulated by the device was recorded while the subject was standing still after passing the goal line (Fig. 2). The walking path used in this study was one that is frequently used during rehabilitation in this hospital. Before the walking test, subjects practiced until the test was performed correctly. The walking tests were performed four times, once for each type of device. During the first test, 18 participants attached the AS to one side and the LC to the other side. During the second test, the sides of the AS and LC were exchanged. During the third and fourth tests, WS and 
ST were attached in the same way as that used for AS and LC. The remaining 43 subjects attached the same types of devices to the affected and unaffected sides in the following order: LC, AS, WS, and ST.

The affected and unaffected sides were established by a physical therapist. The main disease state and complications experienced by the patients were taken into consideration. The side on which the leg deviated more from a normal walking pattern was classified as the affected side: the other side was the unaffected side.

\section{Data Analysis}

The following data were calculated (units):

(1) Number of steps recorded on the devices (steps) $=$ the post-walking test number of steps - the prewalking test number of steps

(2) Measurement error (ME: \%)

$=$ (the number of steps recorded on the device - actual steps)/ actual steps $\times 100$

(3) Gait velocity $(\mathrm{m} / \mathrm{s})$

$=25(\mathrm{~m}) /$ walking time $(\mathrm{s})$

(4) Step length (m)

$=25(\mathrm{~m}) /$ actual steps (steps)

(5) Cadence (steps/s)

= actual steps (steps)/ walking time (s)

Gait velocities were compared for each combination of device and attachment position. A Friedman analysis was performed. Multiple comparisons using the Bonferroni method were performed as a post hoc analysis. The level of significance was set as 5\%. Measurements with an ME score of $\pm 3 \%$ (according to the first ME standard, using the Japanese Industrial Standard pedometer JIS S 720019) or an ME score of $\pm 10 \%$ (according to the second ME standard) were classified as the valid group: measurements with $\mathrm{ME}$ scores greater than $3 \%$ or $10 \%$ or lower than $-3 \%$ or $-10 \%$, according to the respective ME standard, were classified as the invalid group. An ME of $\pm 10 \%$ was used because previous studies ${ }^{12,13,18)}$ that examined the validity of step counts for healthy subjects using the same devices as those used in this study found that ME was within approximately $\pm 10 \%$ at low gait velocities (approximately $0.90 \mathrm{~m} / \mathrm{s}$ ).

In addition, the following analysis was used to obtain useful cut-off values and to exclude invalid step counts as much as possible (Fig. 3). A receiver-operator characteristic (ROC) curve (dependent variable: valid group versus invalid group; independent variables: gait velocity, step length, and cadence) was used. The values for the cut-off velocity (COV), cut-off step length (COS), and cut-off cadence (COC) were determined at a specificity of 0.95 . Moreover, the sensitivity, the positive predictive value (PPV), and the number of data points classified in the valid group and above the cut-off values (number of valid data [NVD]) were calculated for each cut-off value. These cut-off values were established so that $95 \%$ of the invalid group could accurately be excluded. Furthermore, based on the report of Sekine et al., ${ }^{20)}$ the cutoff value criteria were set at $>0.40$ sensitivity and $>80 \% \mathrm{PPV}$. The calculated cut-off values that met these criteria were utilized. Using these criteria, cut-off values were used only if they included more than $40 \%$ of the data in the valid group and more than $80 \%$ of NVD in the data above the cut-off value. In the ROC curve analysis, Youden's index was not adopted to set the cut-off values. This was because some cut-off values derived using Youden's index include many invalid data points, despite a high area under the curve. For this reason, specificity was instead used to set the cut-off value. ROC curve analysis was performed using IBM SPSS Statistics Version 24 (IBM Corp, Chicago, IL, USA).

\section{RESULTS}

The mean \pm standard deviation (SD) baseline walking parameters of the subjects were as follows: gait velocity, 0.75 $\pm 0.26 \mathrm{~m} / \mathrm{s}$; step length, $0.43 \pm 0.10 \mathrm{~m}$; and cadence, $1.71 \pm$ $0.29 \mathrm{steps} / \mathrm{s}$ (Table 1). A comparison of gait velocities for the investigated combinations of devices and attachment positions is presented in Fig. 4. The gait velocity measured using AS or LC was significantly lower than that measured using WS or ST $(\mathrm{P}<0.05)$. The means \pm SDs of the MEs for devices that underestimated the number of steps were as follows: AS attached to the unaffected side, $-29.7 \pm 37.6 \%$; AS attached to the affected side, $-38.0 \pm 38.4 \%$; WS attached to the unaffected side, $-23.7 \pm 32.0 \%$; WS attached to the affected side, $-24.1 \pm 32.2 \%$; LC attached to the unaffected side, $-40.9 \pm 32.7 \%$; LC attached to the affected side, -43.5 $\pm 34.7 \%$; ST attached to the unaffected side, $-42.9 \pm 46.6 \%$; and ST attached to the affected side, $-40.0 \pm 47.0 \%$.

Cut-off values and scatter diagrams of walking parameters and MEs for each combination of device and attachment position are given in Fig. 5. The total number of values classified in the valid group for each combination of device, ME standard, and attachment position was as follows: 16 (AS, 3\%, unaffected side); 14 (AS, 3\%, affected side); 29 (AS, 10\%, unaffected side); 23 (AS, 10\%, affected side); 15 (WS, 3\%, unaffected side); 23 (WS, 3\%, affected side); 33 (WS, $10 \%$, unaffected side); 31 (WS, 10\%, affected side); 4 (LC, 3\%, unaffected side); 5 (LC, 3\%, affected side); 13 (LC, 


$$
\operatorname{ME}(\%), \mathrm{n}=61
$$

MEs for each combination of one device and one attachment position.

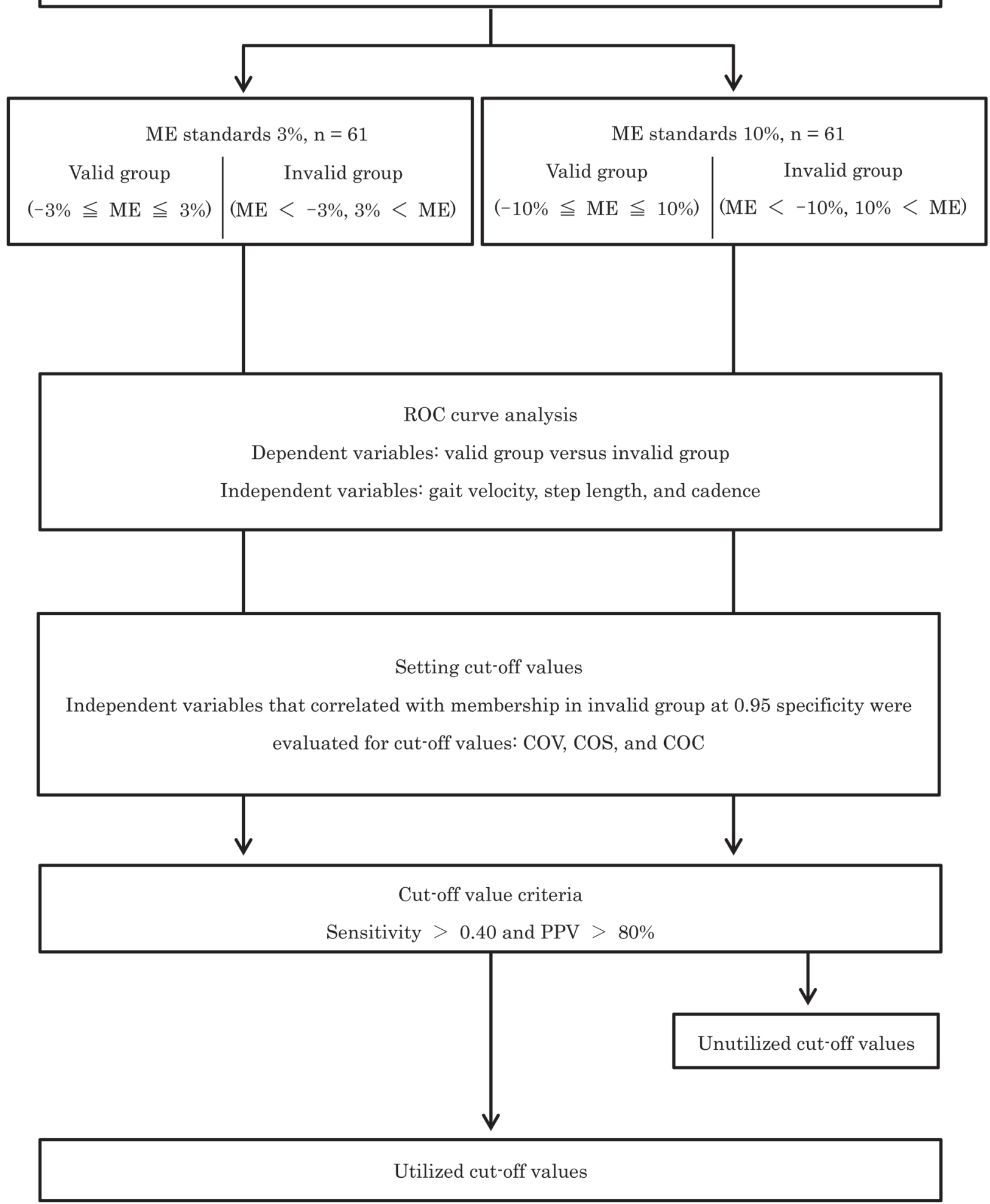

Fig. 3. Flow diagram of analysis to obtain cut-off values.

ME: measurement error; ROC: receiver-operator characteristic; COV: cut-off velocity; COS: cut-off step length; COC: cut-off cadence; PPV: positive predictive value. 


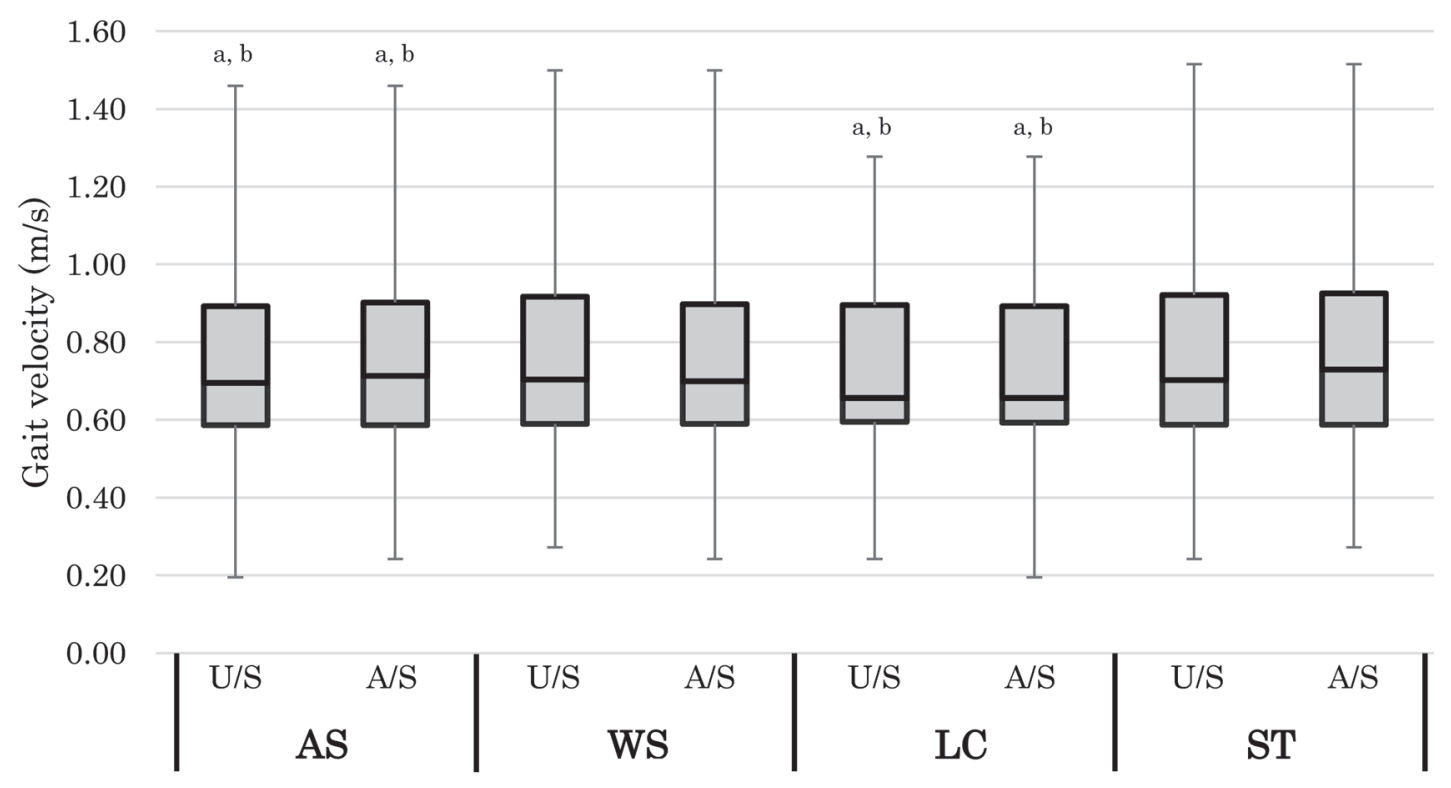

Fig. 4. Comparison of gait velocity by device and attachment position.

Data were analyzed using the Friedman method. The Bonferroni method was used for multiple comparisons as a post hoc analysis. The level of significance was set as $5 \%$. a: Significant difference with WS ( $\mathrm{P}<0.05)$, b: significant difference with ST $(\mathrm{P}<0.05)$.

$10 \%$, unaffected side), 12 (LC, 10\%, affected side); 4 (ST, $3 \%$, unaffected side); 8 (ST, 3\%, affected side); 11 (ST, 10\%, unaffected side); and 15 (ST, 10\%, affected side).

The COV and COS cut-off values of AS and WS were generally lower than those of LC and ST. Regarding the relationship between cut-off values and the distribution of data for walking parameters, many valid data points (for both the $3 \%$ and $10 \%$ ME standards) and a few invalid data points had a faster gait velocity than COV and a larger step length than COS when using AS and WS. However, only a few valid data points had greater values than COV and COS when using LC and ST. Regarding cut-off cadence (COC), a few valid data points had a cadence greater than COC, regardless of the device type. The utilized cut-off values for $3 \% \mathrm{ME}$ standards were as follows: $\mathrm{COV}, 0.90 \mathrm{~m} / \mathrm{s}$ (AS and unaffected side); COS, $0.52 \mathrm{~m}$ (AS and unaffected side); and $\mathrm{COV}, 0.98 \mathrm{~m} / \mathrm{s}$ (WS and affected side). Those for 10\% ME standards were as follows: $\mathrm{COV}, 0.90 \mathrm{~m} / \mathrm{s}$ (AS and affected or unaffected side); COS, $0.50 \mathrm{~m}$ (AS and affected side); and $\mathrm{COV}, 0.92 \mathrm{~m} / \mathrm{s}$ (WS and unaffected side). The cut-off values for the LC and ST devices and the cut-off cadence (COC) for walking parameters did not satisfy the criteria of sensitivity $>0.40$ and PPV $>80 \%$ and so were not utilized (Table 3). Scatter diagrams of ME and gait velocity for each combination of device and attachment position are given in Fig. 6. It was recognized that ME scores within $\pm 3 \%$ or $\pm 10 \%$ tended to coincide with a faster gait velocity when the COV met the sensitivity and PPV criteria and could be utilized.

\section{DISCUSSION}

The conditions under which it is possible to measure valid step counts were identified in this study. The data indicated that measurements were more reliable when the patient had a comfortable gait velocity higher than $0.90 \mathrm{~m} / \mathrm{s}$ and the AS device was attached on the unaffected side. This is because the NVD for the same ME standard was greater using COV than when using COS (Fig. 5 and Table 3). Regarding differences between devices, the COV for AS was lower than the COV for WS. This means that the conditions for measuring valid step counts are less restrictive when using AS than when using WS. Regarding the attachment position, the ME when AS was attached to the unaffected side was smaller than the ME when AS was attached to the affected side. Moreover, attaching AS to the unaffected side satisfied the 3\% ME standard, whereas attaching AS to affected side did not.

In this study, some walking parameter cut-off values for gait velocity and step length could be utilized. It was found that gait velocity greatly influenced the accuracy of step- 

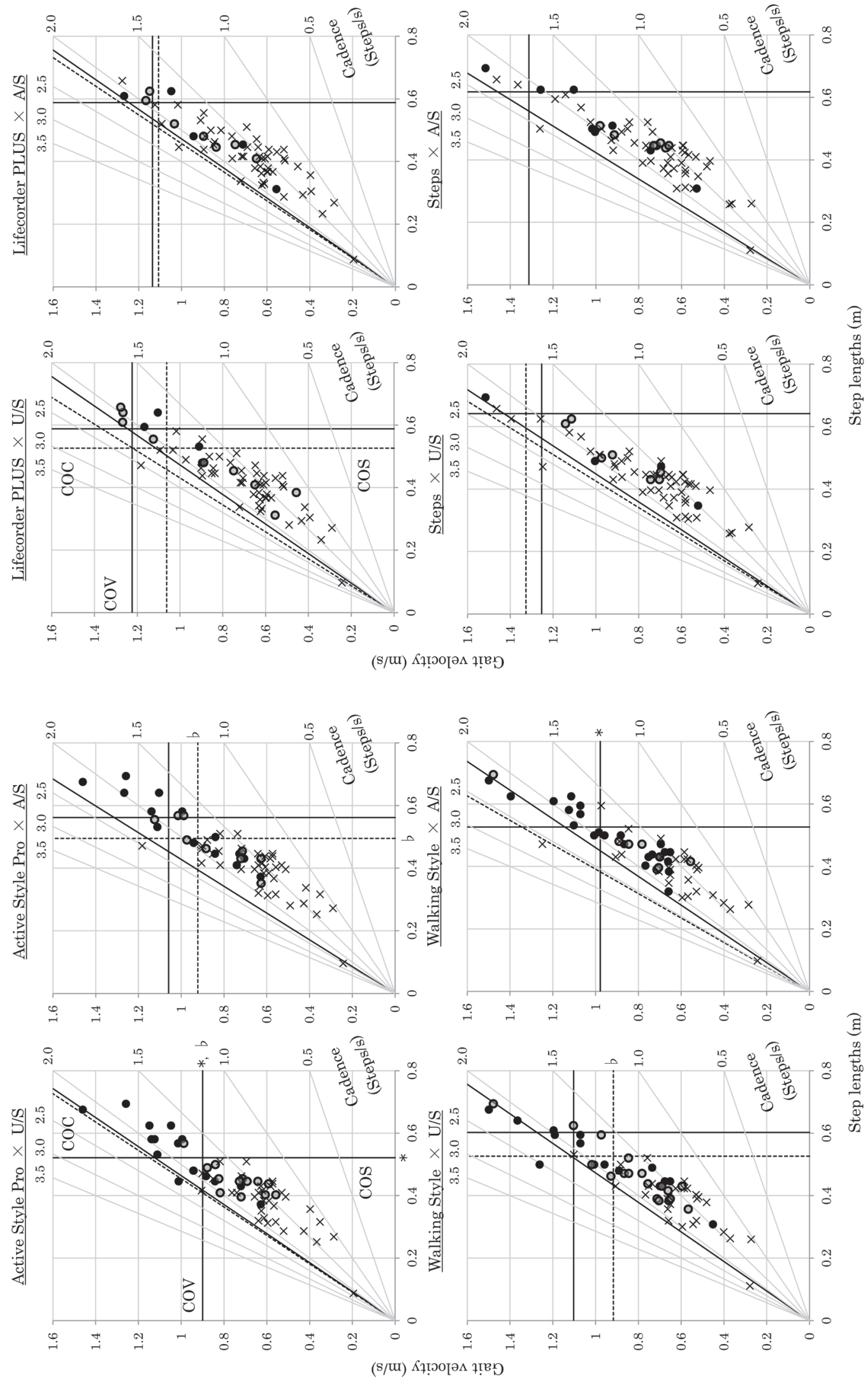

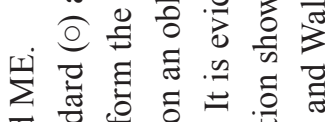

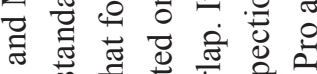

की के एँ की

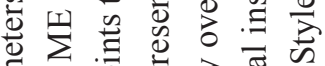

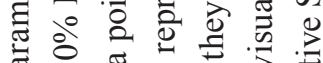

䒕을

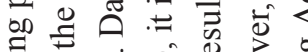

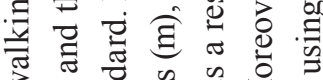

30 त

फ

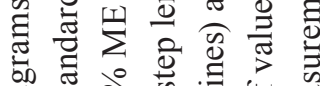

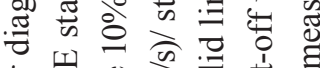

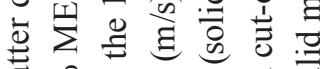

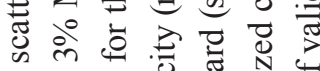

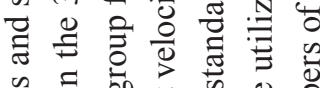

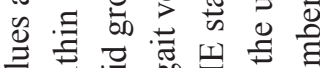

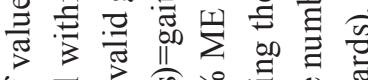

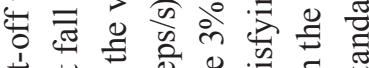

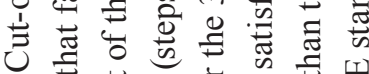

ம

ம) 
Table 3. Utilized cut-off values, sensitivity, PPV, and NVD

\begin{tabular}{cccccrr}
\hline $\begin{array}{c}\text { ME standard } \\
(\%)\end{array}$ & $\begin{array}{c}\text { Walking } \\
\text { parameter }\end{array}$ & $\begin{array}{c}\text { Attachment } \\
\text { position }\end{array}$ & $\begin{array}{c}\text { Cut-off values } \\
(\mathrm{m} / \mathrm{s} \text { or m) }\end{array}$ & Se & $\begin{array}{r}\text { PPV } \\
(\%)\end{array}$ & NVD $^{\mathrm{a}}$ \\
\hline $\begin{array}{c}\text { Active Style Pro } \\
3 \%\end{array}$ & $\mathrm{COV}$ & $\mathrm{U} / \mathrm{S}$ & 0.90 & 0.75 & 85.7 & 12 \\
& $\mathrm{COS}$ & $\mathrm{U} / \mathrm{S}$ & 0.52 & 0.56 & 90.0 & 9 \\
$10 \%$ & $\mathrm{COV}$ & $\mathrm{U} / \mathrm{S}$ & 0.90 & 0.45 & 92.9 & 13 \\
& $\mathrm{COV}$ & $\mathrm{A} / \mathrm{S}$ & 0.90 & 0.52 & 85.7 & 12 \\
& $\mathrm{COS}$ & $\mathrm{U} / \mathrm{S}$ & 0.52 & 0.35 & 100.0 & 10 \\
& $\mathrm{COS}$ & $\mathrm{A} / \mathrm{S}$ & 0.50 & 0.48 & 84.6 & 11 \\
\hline Walking Style & & & & & & \\
$3 \%$ & $\mathrm{COV}$ & $\mathrm{A} / \mathrm{S}$ & 0.98 & 0.43 & 83.3 & 10 \\
$10 \%$ & $\mathrm{COV}$ & $\mathrm{U} / \mathrm{S}$ & 0.92 & 0.42 & 93.3 & 14 \\
& $\mathrm{COV}$ & $\mathrm{A} / \mathrm{S}$ & 0.98 & 0.36 & 93.3 & 11 \\
\hline
\end{tabular}

Se: sensitivity; PPV: positive predictive value; NVD: number of valid data.

${ }^{\text {aT }}$ The number of data that were classified in the valid group and were above the cut-off values.

bValues given for reference only because the cut-off values for the 3\% ME standard were utilized, but that for the $10 \% \mathrm{ME}$ standard were not utilized. The cut-off values are the same for the 3\% ME and 10\% ME standards. Se, PPV, and NVD are at the $10 \%$ ME standard.

count measurements. Previous studies ${ }^{13,14,18)}$ have reported the accuracy of step-count measurements for healthy people walking on a treadmill with different gait velocities. However, each of these reports set lower limits of gait velocity at approximately $0.90 \mathrm{~m} / \mathrm{s}$, and several devices underestimated the number of steps at such a low gait velocity. Each activity monitor uses a device-specific algorithm for step-count measurements; however, the devices use the same mechanism of sensing acceleration during walking and are able to detect the number of steps when the acceleration exceeds the cut-off point. The acceleration generated at the waist during walking (excluding gravitational acceleration) is the acceleration component of the ground reaction force (GRF) force $(F=m a$; F, force; $\mathrm{m}$, mass; a, acceleration) generated when the foot strikes the ground. The GRF is transmitted to the hip via the ankle, knee, hip, and other joints. A positive correlation between gait velocity and the magnitude of the acceleration at the waist during walking has been reported ${ }^{21)}$; indeed, it has been found that reduced gait velocity leads to a lower acceleration at the waist. If the acceleration does not reach the cut-off point for a specific device to detect steps, then the number of steps will be underestimated. ${ }^{12,13)}$ This suggests that gait velocity is a more useful cut-off index than step length and cadence are.

Although different results occurred only with $\mathrm{LC}$, the devices used in this study reportedly yield valid step-count measurements for healthy people at a gait velocity of approximately $0.90 \mathrm{~m} / \mathrm{s}$. In healthy volunteers, the following ME values for the devices have been evaluated: $\mathrm{AS},-0.8 \%{ }^{13)}$; WS, $1.5 \%{ }^{18)}$; LC, $-8.2 \%{ }^{13)}$ or approximately $-11 \%{ }^{12)}$; and ST, approximately $10 \%{ }^{12)}$ It was noted that there was a significant difference between the actual number of steps taken and the number of steps measured when using the LC device. ${ }^{13)}$ The devices used in the current study (apart from AS) could not measure valid step counts for our population at a gait velocity of $0.90 \mathrm{~m} / \mathrm{s}$, although they are reportedly accurate for healthy people walking at the same gait velocity. ${ }^{12,13,18)}$ In the current study, the results were influenced by gait abnormality and device performance. The acceleration at the lower back (the L3-L4 vertebrae) ${ }^{21,22)}$ and the GRF ${ }^{23,24)}$ have been investigated for subjects with gait abnormality. Moreover, differences in the acceleration or GRF between subjects with normal and abnormal gaits and differences in the acceleration or GRF between the unaffected side and the affected side have been reported. Regarding device performance, there are differences in the number of accelerometer axes (AS, triaxial accelerometer; LC, uniaxial accelerometer), the acceleration resolution (AS, $3 \mathrm{mG}$; $\mathrm{LC}, 60 \mathrm{mG}$ ), and the acceleration measurement range (AS, \pm 6 G; LC, 0.06-1.94 G). ${ }^{10,13,25)}$ Furthermore, differences in the algorithms used by the devices probably affected the results. However, it was not possible to examine the algorithms because their details are not publicly available. It is believed that all these factors influenced step-count measurements; therefore, the results of the current study differed from the results of previous studies. ${ }^{12,13,18)}$ 

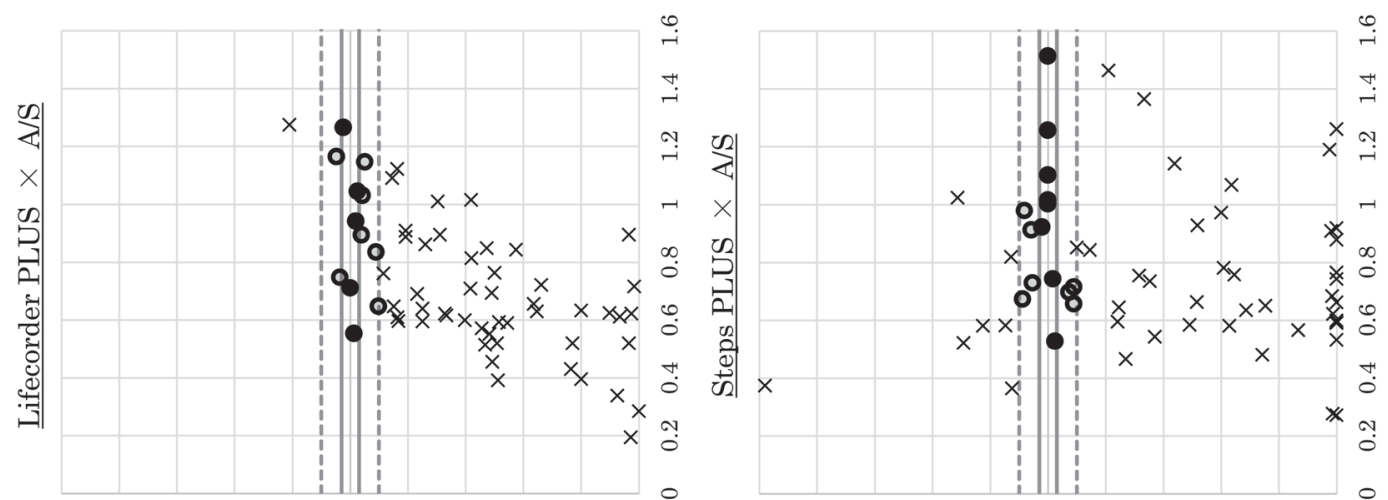

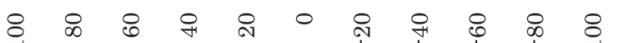
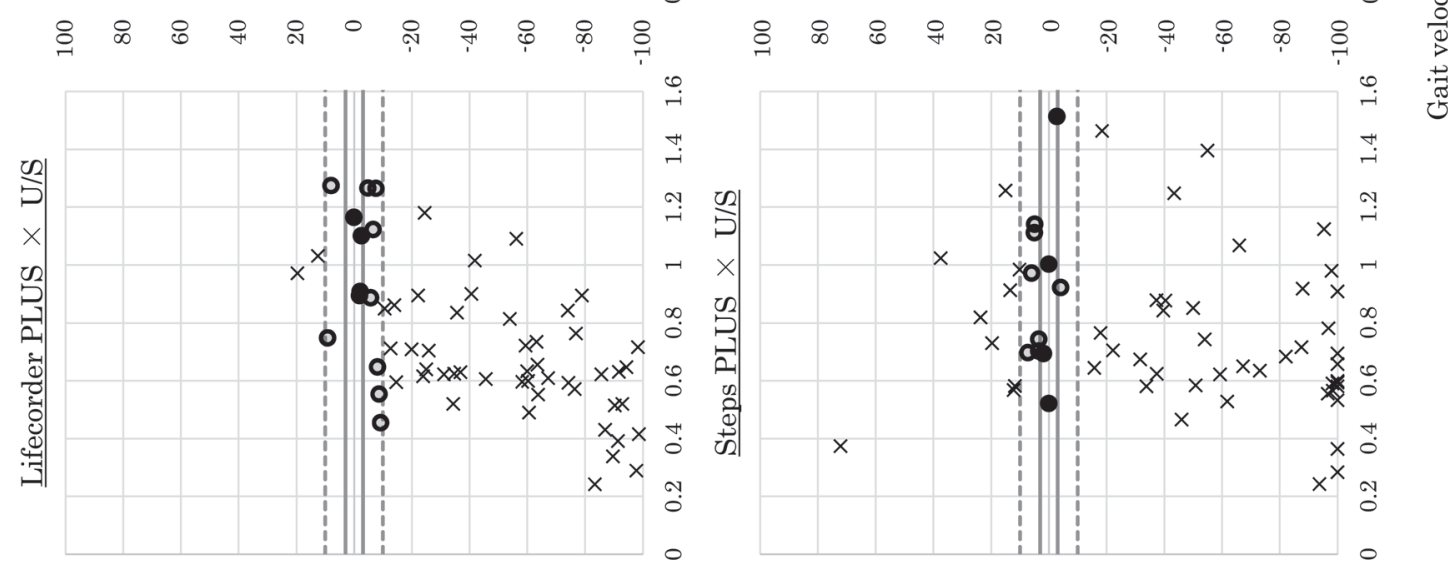

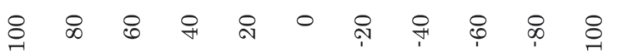

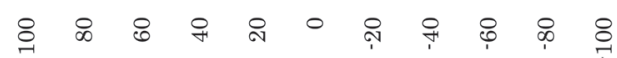

(\%) холлә ұนәшәлпsеәN
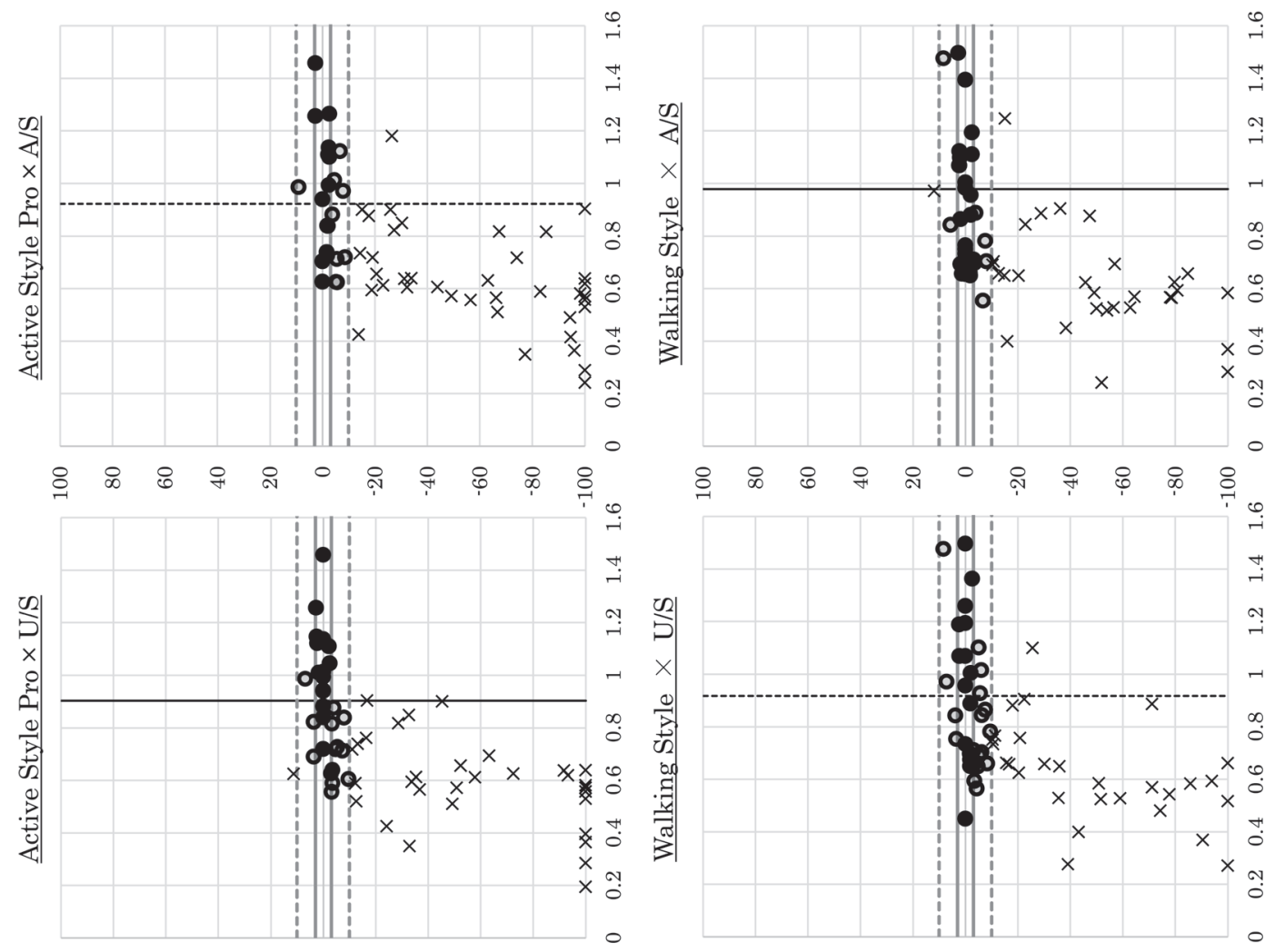

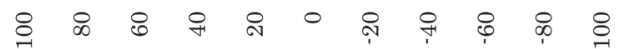

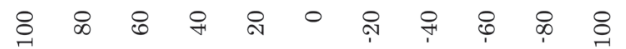

(\%) холљә ұиәшәлимеәџ

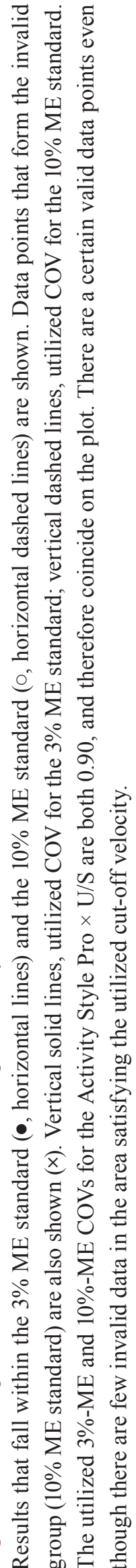


Cut-off values using LC were not utilized in this study. This may have been influenced by the lower gait velocity measured using LC compared with those using WS and ST (Fig. 4). The measured values using LC could not meet the cut-off value criteria (sensitivity $>80 \%$ and PPV $>0.40$ ), likely because there were not enough measured values in the fast gait velocity range using LC. In contrast, multiple cut-off values were identified with AS, despite the low gait velocity compared with WS and ST. Therefore, the influence on low gait velocity observed with AS was not strong compared with LC.

\section{Limitations}

Silcott et al. ${ }^{26)}$ reported a difference in the validity of stepcount measurements between laboratory settings (such as walking on a treadmill) and free-living conditions (such as usual daily activities). AS counts steps when the magnitude of the measured acceleration is above the cut-off point and this magnitude lasts more than $2 \mathrm{~s}{ }^{16}$ ) WS counts steps when walking lasts more than $4 \mathrm{~s} .{ }^{26}$ ) It is suspected that these differences influence the step-count measurements of intermittent walking activities and walking in free-living conditions (such as activities of daily living). Our study design involved only the laboratory setting; it would be useful to measure step counts during continuous walking activities outdoors or in a large exercise area for hospitalized patients. However, it is possible that the current study design is unsuitable for measuring step counts during activities that do not involve sustained walking, such as getting up to place something on a table and then sitting down again.

Another limitation of this study was that the conditions of the walking tests could not be completely adjusted because the gait velocities using AS and LC were lower than those using WS and ST. This difference in gait velocities might have been influenced by the order in which the devices were used. AS and LC were used first or second. The path used for the walking test is frequently used during rehabilitation. In addition, the subjects practiced more than once before taking the walking test. However, it is assumed that subjects walked more carefully in the early tests than in the later tests because they gained confidence as the tests progressed. If the order of device use had been randomized in the walking test, then this influence could have been excluded.

The activity monitors used in this study made it possible to measure the amount of physical activity. However, the focus was on the number of steps. Therefore, the results of this study are not useful for all forms of physical activity. Evaluation and quantitation of the amount of physical activity of patients with abnormal gait are challenges for future studies.

\section{CONCLUSIONS}

In this study, the conditions that allow the measurement of valid step counts in subjects with abnormal gait were identified. The results indicated that valid step-count measurements are more likely to be obtained for patients with abnormal gait when the comfortable gait velocity is higher than $0.90 \mathrm{~m} / \mathrm{s}$ and the AS device is used on the unaffected side.

\section{ACKNOWLEDGMENTS}

We thank the members of Kyoto Hakuaikai Social Welfare Corporation, Kyoto Hakuaikai Hospital, and Doshisha University Health and Human Performance Laboratory. Heartfelt thanks are extended to the subjects who participated in the present study.

\section{ETHICAL CONSIDERATIONS}

Ethical approval was obtained from the Doshisha University of Human Subject Research Ethics Committee (approval number 14028).

\section{CONFLICTS OF INTEREST}

None of the authors has any conflicts of interest to declare.

\section{REFERENCES}

1. English C, Healy GN, Olds T, Parfitt G, Borkoles E, Coates A, Kramer S, Bernhardt J: Reducing sitting time after stroke: a phase II safety and feasibility randomized controlled trial. Arch Phys Med Rehabil 2016;97:273-280. PMID:26529471, DOI:10.1016/j. apmr.2015.10.094

2. Jones TM, Hush JM, Dear BF, Titov N, Dean CM: The efficacy of self-management programmes for increasing physical activity in community-dwelling adults with acquired brain injury (ABI): a systematic review. Syst Rev 2014;3:39-44. PMID:24745356, DOI:10.1186/2046-4053-3-39

3. Brown CJ, Friedkin RJ, Inouye SK: Prevalence and outcomes of low mobility in hospitalized older patients. J Am Geriatr Soc 2004;52:1263-1270. PMID:15271112, DOI:10.1111/j.1532-5415.2004.52354.x 
4. Chudyk AM, Jutai JW, Petrella RJ, Speechley M: Systematic review of hip fracture rehabilitation practices in the elderly. Arch Phys Med Rehabil 2009;90:246-262. PMID:19236978, DOI:10.1016/j.apmr.2008.06.036

5. Chodzko-Zajko WJ, Proctor DN, Fiatarone Singh MA, Minson CT, Nigg CR, Salem GJ, Skinner JS, American College of Sports Medicine: American College of Sports Medicine position stand. Exercise and physical activity for older adults. Med Sci Sports Exerc 2009;41:1510-1530. PMID:19516148， DOI:10.1249/ MSS.0b013e3181a0c95c

6. Gebruers N, Vanroy C, Truijen S, Engelborghs S, De Deyn PP: Monitoring of physical activity after stroke: a systematic review of accelerometry-based measures. Arch Phys Med Rehabil 2010;91:288-297. PMID:20159136, DOI:10.1016/j.apmr.2009.10.025

7. Tudor-Locke C, Craig CL, Aoyagi Y, Bell RC, Croteau KA, De Bourdeaudhuij I, Ewald B, Gardner AW, Hatano Y, Lutes LD, Matsudo SM, Ramirez-Marrero FA, Rogers LQ, Rowe DA, Schmidt MD, Tully MA, Blair SN: How many steps/day are enough? For older adults and special populations. Int J Behav Nutr Phys Act 2011;8:80-99.

8. Ogilvie D, Foster CE, Rothnie H, Cavill N, Hamilton V, Fitzsimons CF, Mutrie N, Scottish Physical Activity Research Collaboration: Interventions to promote walking: systematic review. BMJ 2007;334(7605):12041213. PMID:17540909, DOI:10.1136/bmj.39198.722720. $\mathrm{BE}$

9. Mansi S, Milosavljevic S, Baxter GD, Tumilty S, Hendrick P: A systematic review of studies using pedometers as an intervention for musculoskeletal diseases. BMC Musculoskelet Disord 2014;15:231-243. PMID:25012720, DOI:10.1186/1471-2474-15-231

10. Sasai H, Hikihara Y, Okazaki K, Nakata Y, Ohkawara $\mathrm{K}$ : Overview of physical activity assessments by accelerometer-based activity monitors and their potential application for physical activity promotion. Jpn Assoc Exerc Epidemiol. 2015;17:6-18 [In Japanese].

11. Stretton CM, Mudge S, Kayes NM, McPherson KM: Interventions to improve real-world walking after stroke: a systematic review and meta-analysis. Clin Rehabil 2017;31:310-318. PMID:27056251, DOI:10.1177/0269215516640863

12. Crouter SE, Schneider PL, Karabulut M, Bassett DR Jr: Validity of 10 electronic pedometers for measuring steps, distance, and energy cost. Med Sci Sports Exerc
2003;35:1455-1460. PMID:12900704, DOI:10.1249/01. MSS.0000078932.61440.A2

13. Park J, Ishikawa-Takata K, Tanaka S, Mekata Y, Tabata I: Effects of walking speed and step frequency on estimation of physical activity using accelerometers. J Physiol Anthropol 2011;30:119-127. PMID:21636955, DOI:10.2114/jpa2.30.119

14. Carroll SL, Greig CA, Lewis SJ, McMurdo ME, Sniehotta FF, Johnston M, Johnston DW, Scopes J, Mead GE: The use of pedometers in stroke survivors: are they feasible and how well do they detect steps? Arch Phys Med Rehabil 2012;93:466-470. PMID:22373934, DOI:10.1016/j.apmr.2011.08.047

15. Inman VT: Human locomotion. Can Med Assoc J 1966;94:1047-1054. PMID:5942660

16. Oshima Y, Hikihara Y, Ohkawara K, Ishikawa-Takata K, Miyake R, Ebine N, Tabata I, Tanaka S: Daily steps corresponding to the reference quantity of physical activity of Exercise and Physical Activity Reference for health promotion 2006 (EPAR2006) assessed by accelerometer. Jpn J Phys Fit Sport Med. 2012;61:193-199 [In Japanese]. DOI:10.7600/jspfsm.61.193

17. Nakae S, Oshima Y, Ishii K: Accuracy of spring-levered and piezo-electric pedometers in primary school Japanese children. J Physiol Anthropol 2008;27:233-239. PMID:18838838, DOI:10.2114/jpa2.27.233

18. Giannakidou DM, Kambas A, Ageloussis N, Fatouros I, Christoforidis C, Venetsanou F, Douroudos I, Taxildaris K: The validity of two Omron pedometers during treadmill walking is speed dependent. Eur J Appl Physiol 2012;112:49-57. PMID:21479653

19. Japanese Industrial Standards 720 S: pedometer. 1993. http://kikakurui.com/s/S7200-1993-01.html. Accessed February 27, 2017.

20. Sekine M, Kuwae Y, Tamura T, Kijima Y, Yuji T, Higashi Y, Fujimoto T: Quantification of walking independence measure in hemiplegic patients using wearable motion sensor. Trans Jpn Soc Med Biol Eng. 2011;49:212-219 [In Japanese].

21. Sekine M, Tamura T, Yoshida M, Suda Y, Kimura Y, Miyoshi H, Kijima Y, Higashi Y, Fujimoto T: A gait abnormality measure based on root mean square of trunk acceleration. J Neuroeng Rehabil 2013;10:118-124. PMID:24370075, DOI:10.1186/1743-0003-10-118

22. Yamada M, Hirata S, Ono R, Ando H: The assessment of an abnormal gait by gait parameters derived from trunk acceleration in patients with osteoarthritis of the hip - comparison with healthy controls and criterion- 
related validity. J Jpn Phys Ther Assoc 2006;33:14-21 [In Japanese].

23. McCrory JL, White SC, Lifeso RM: Vertical ground reaction forces: objective measures of gait following hip arthroplasty. Gait Posture 2001;14:104-109. PMID:11544061, DOI:10.1016/S0966-6362(01)00140-0

24. White R, Agouris I, FletcherE: Harmonic analysis of force platform data in normal and cerebral palsy gait. Clin Biomech (Bristol, Avon) 2005;20:508-516. PMID:15836938, DOI:10.1016/j.clinbiomech.2005.01.001
25. Ohkawara K, Oshima Y, Hikihara Y, Ishikawa-Takata K, Tabata I, Tanaka S: Real-time estimation of daily physical activity intensity by a triaxial accelerometer and a gravity-removal classification algorithm. Br J Nutr 2011;105:1681-1691. PMID:21262061, DOI:10.1017/S0007114510005441

26. Silcott NA, Bassett DR Jr, Thompson DL, Fitzhugh EC, Steeves JA: Evaluation of the Omron HJ-720ITC pedometer under free-living conditions. Med Sci Sports Exerc 2011;43:1791-1797. PMID:21311356, DOI:10.1249/MSS.0b013e318212888c 